\title{
Designing a Feedback Based Diagnosis Decision Support Tool for Continuous Improvement of e-Readiness Indices to Implement e-Government
}

\author{
Hamed Fazlollahtabar \\ Faculty of Industrial Engineering, Iran University of Science and Technology, Tehran, Iran \\ *Corresponding Author: hfazl@iust.ac.ir
}

Copyright $(2013$ Horizon Research Publishing All rights reserved.

\begin{abstract}
Information Technology (IT) has played a significant role in facilitating organizational change programs. Many countries have tried to implement electronic government (e-government) as the most basic infrastructure for such programs. The term electronic government (e-government) is mainly inferred from the information and communications technology (ICT) usage to modify structures and procedures of government agencies. Acknowledging the necessity of utilizing the new electronic, information, and communication technologies, the movement toward implementation of e-government got the attention of authorities and policy makers.

Public administrations have been very much concerned about the architecture of e-government, especially because of the promotion of e-government that has taken place in recent years. The paper seeks to provide a set of electronic readiness (e-readiness) indices affecting e-government overall architecture. The paper notes the various major segments of e-readiness. The paper proposes a feedback based diagnosis system (FBDS) as e-readiness integrated tool that emphasizes information access and also integrates the various segments of organizational, ICT, human resources, and external readiness into one single tool.
\end{abstract}

Keywords e-Government, e-Readiness, Diagnosis System

\section{Introduction}

The last decade has experienced a revolution in information and communication technologies (ICT). This revolution is not only affecting the daily lives of people but is also changing the concepts of interactions between governments and citizens. These changes, has lead to a transformation of new forms of government named electronic government (e-government). Of course, considering different applications of Information Technology (IT) such as electronic commerce, e-learning, and stories of success and failure, it is inevitable to reach the e-government movement (Layne \& Lee, 2001).

Moreover, after financial institutions, the public consumers are the second largest market of the Internet applications (Shutter \& Graffenreid, 2000).

E-government is defined as "utilizing the Internet and the World-Wide-Web for delivering government information and services to citizens", (United Nations \& American Society for Public Administration, 2002, p. 1). Also, some other structures of IT such as "database, networking, discussion support, multimedia, automation, tracking and tracing, and personal identification technologies" can be included in e-government. (Jaeger, 2003). Means and Schneider (2000, p. 121) define e-government as the relationships between governments, their customers (such as businesses and citizens), and their suppliers (like businesses and other governmental agencies) by means of electronic technologies.

E-government has the capability to help build better relationships between government and the public by providing interactions smoother, easier, and more efficient.

The traditional model of government is not working any longer. The emerging extensive networks of interacting public, private, and voluntary organizations could not be served using the traditional configurations of single administrations for single services and specific functions (Batista et al., 2013). Responding to sophisticated problems of communities and presenting solutions could only be provided through collaboration between government body members, and also with internal as well as external entities, including other governments (Georgoulas et al., 2013). In fact, governments have started to realize the vital necessity of modernization in order to make improvements and strengthen and sustain their position in the global competition. Traditional business models should be replaced by new one, such as e-commerce. Indeed, achieving such a situation would not be possible in the existence of inefficient and ineffective organizations and processes. This fact is a major concern for many countries especially in the developing world (Schware \& Deane, 2003).

E-Government has become a global phenomenon. Both industrialized and developing countries have been affected by e-Government strategies and projects, the latter typically with support from donor organizations such as the World Bank or bilateral donor organizations. 


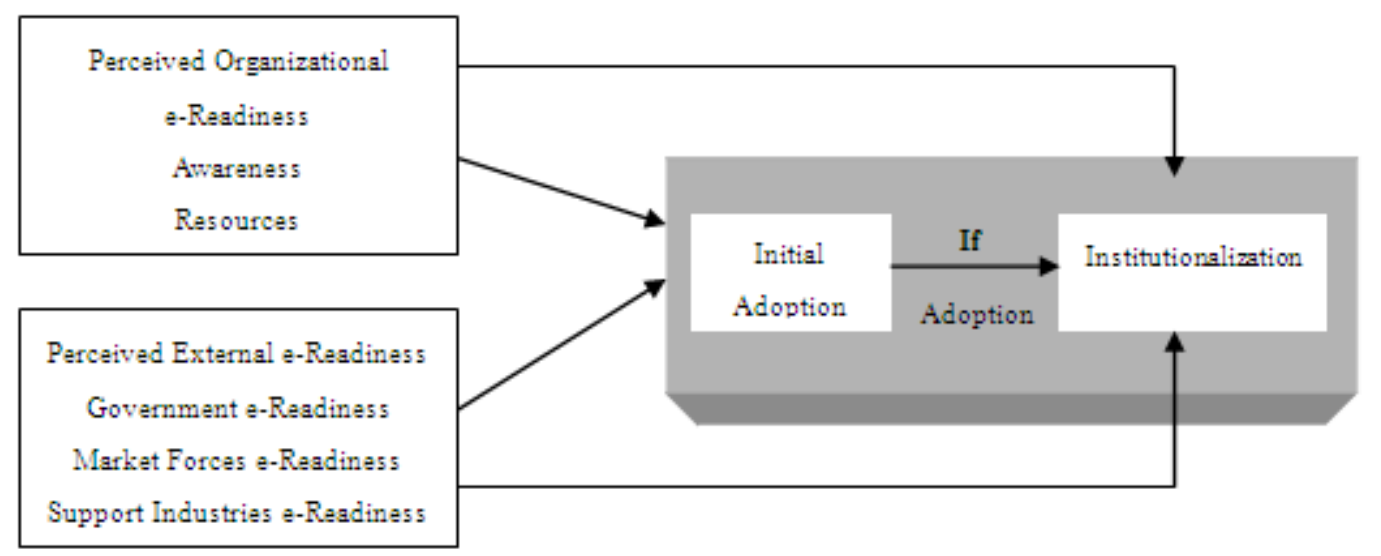

Figure 1. E-readiness model

Under the label "Information and Communication Technologies for Development" (ICT4D), these organizations are insisting on the relevance of Information and Communication Technologies (ICT) in general, and E-Government in particular, as a way to advance life style and reduce poverty. E-Government is seen as strengthening the functionality of government and public administration, and an efficient and effective state administration is a necessary prerequisite for economic and social development.

\section{E-Readiness Models and Concepts}

Recently, several models for e-readiness assessment of countries at macro level have been presented by different organizations. On the surface, each model gauges how ready a society or economy is to benefit from IT and e-commerce. With more in depth consideration, the models use varying definitions for e-readiness and different methods for evaluation. These e-readiness assessment models are mainly divided into four categories:

1. Ready-to-use tools: There are few ready-to-use tools freely available on the web.

2. Case studies: There are numerous case studies assessing specific countries' e-readiness, and many of these could be used as principals for e-readiness tools.

3. Third party surveys and reports: These reports aim to rank and rate countries based on various measures held to indicate e-readiness.

4. Other e-readiness assessment models: In addition to the formal tools and surveys stated above, there is a range of other frameworks such as digital divide reports and position papers that can be similarly used for e-readiness assessment (Tavana et al. 2013).

There are several definitions for e-readiness. The CSPP model defines an "e-ready" community as one that has: high-speed access in a competitive market; with constant access and application of ICTs in schools, government offices, businesses, healthcare facilities, and homes; user privacy; online security and government policies which are favorable to expanding connectedness and using the network (Janita \& Chong, 2013). The Asian Pacific Economic Cooperation (APEC) group defines a country as e-ready if it demonstrates e-commerce, has free trade, industry self-regulation, ease of exports, and compliance with international standards and trade agreements. McConnell International defines e-readiness as the capacity of nations to participate in the digital economy. Finally, the Center for International Development (CID) at Harvard University, the most acclaimed institution in e-readiness research, defines an "e-ready" society as one that has the necessary physical infrastructure (high bandwidth, reliability, and affordable prices); integrated current ICTs throughout businesses (e-commerce, local ICT sector), communities (local content, many organizations online, ICTs used in everyday life, ICTs taught in schools), and the government (e-government); strong telecommunications competition; independent regulation with a commitment to universal access and no limits on trade or foreign investment.

While the above-mentioned models concentrate on assessing readiness of countries, governments and policies for adopting information technologies, some others such as IQ Net Readiness Scorecard assess the readiness to adopt other different structures. IQ Net Readiness Scorecard was developed by CISCO and is a Web-based application that assesses an organization's capability to migrate to an Internet Business model. It is based on the book Net Ready (Hartman et al., 2000), which gauges the readiness of IT service providers. An e-readiness model is shown in Figure 1.

Based on the above information and digital literacy competencies models, the following are key segments determined to configure the proposed integrated e-readiness assessment tool (Kaya \& Uyar, 2013).

The tool comprises of five segments, namely information readiness; ICT readiness, enterprise readiness, human resources readiness and external environment readiness. Each segment with the accompanying variables is assumed as generic upon which questions can be drawn when sketching either an interview schedule or a questionnaire for e-readiness assessments (Keramati et al., 2011). The different e-readiness segments should be perceived indicative and a memory aid in developing instruments for data collection during e-readiness assessments. The key segments of the model are depicted diagrammatically in Figure 2. 


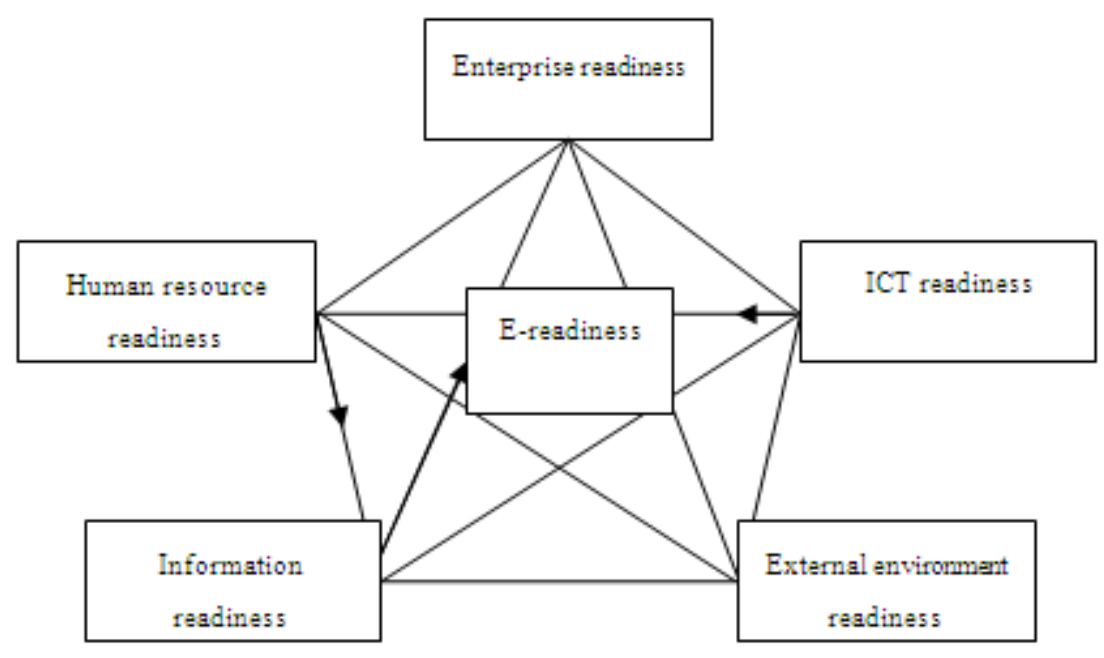

Figure 2. An integrated information e-readiness assessment tool

Figure 2 clearly depicts the information sector taking its rightful situation within the new e-readiness tool and fills the void that exists in the current e-readiness tools. Moreover, the information viewpoints are also covered under human resources and ICT segments presenting an information rich model.

Segments of proposed integrated e-readiness assessment tool are:

(A) Enterprise e-readiness segment

(B) Human resources readiness segment

(C) Information readiness segment

(D) ICT readiness segment

(E) External environment readiness segment

\section{Feedback Based Diagnosis System}

Diagnosis systems categorize the considered symptoms as being caused by some specific problem, diagnosis class, while advising systems perform such a classification and suggest improving remedies. Most of the general principles and observations from the design of diagnosis systems are used in other tasks that involve pattern classification. We begin with some definitions of diagnosis from the Webster's Dictionary, Diagnosis is defined as:

- the act or process of deciding the nature of a disease or a problem by examination of the symptoms

- a careful examination and analysis of the facts in an attempt to explain or understand something (a diagnosis of the economy)

- a decision or opinion based on such an examination

- a short scientific description for taxonomic classificationIn short, a diagnosis system is a capable system for identifying the root of a problem by testing the observed symptoms. The output of the system is a diagnosis (and possibly an explanation or justification of the same). In many applications of interest, it is desirable for the system to not only identify the possible causes of the problem, but also propose suitable remedies. Such systems are said to be capable of giving advice. Typically a diagnosis system is provided a set of indications, (observations or measurements encoded in some machine readable form) as input. The systems function is to identify a probable motivation that could explain the observed symptoms. In order to perform this function, a diagnosis system clearly requires sufficient knowledge of the area. The necessary knowledge may be engineered into the system by its designers or the system may be evolved with the ability to acquire the necessary domain knowledge on its own through experience. The former approach referred to as knowledge engineering is typically used in the configuration of the diagnostic rules for expert systems or knowledge based systems.

The latter approach relies on the use of machine learning techniques for automated knowledge acquisition Artificial Intelligence (AI) offers a broad spectrum of approaches to intelligent diagnosis each with its own strengths and weaknesses depending (among other things) on the nature of the diagnosis task and the type and amount of domain knowledge that is available. This paper proposes an approach to design an intelligent diagnosis system emphasizing their strengths and limitations.

Based on the evaluation of e-readiness segments, a prototype of the feedback based diagnosis system (FBDS) has been developed. It proposes a multi-criteria evaluation and an integration step, effectiveness and comparison of e-readiness, explanation and justification functionalities of the existing e-readiness effectiveness. The evaluative feedbacks database of e-readiness can be segmented considering the set of criteria. It obviously constitutes a mine of information for the e-government implementation. Indeed, these experience feedbacks are to all the evaluation criteria of e-readiness segments presenting a useful working base to better meet e-government implementation in real-time, to identify weaknesses and strengths e-readiness. The analysis of the e-readiness by its categories presents relevant indicators to monitor and diagnose the consequences of the e-government (Figure 3). 


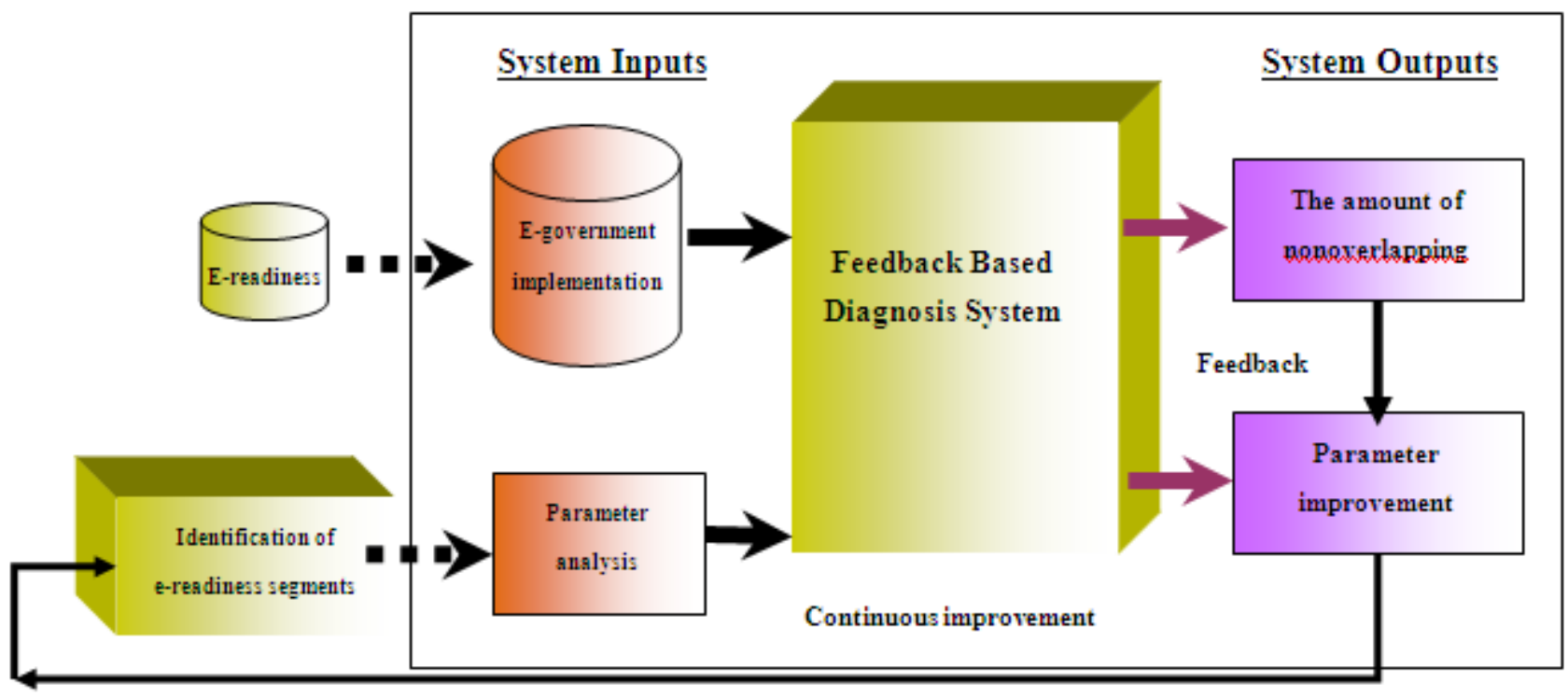

Figure 3. The feedback based diagnosis system

\section{Conclusion}

The importance of information as a vital resource on which organizations and countries depend to assist in the management decision making and competitive advantage has already been underscored. It has been observed that it is becoming increasingly difficult to participate adequately in today's global economy without proper information management as a fundamental part of all productive activity.

Furthermore, the importance of information in economic development demands that a sustainable learning society be established in conjunction with any national economic development plan. The existing e-readiness assessments have largely subsumed the information factor under ICTs and in the process are not appropriate to underscore the importance of information as a critical element in the organizations' or individuals' ability to leverage ICTs in the global information age. The new information rich e-readiness assessment tool is however not expected to be as already pointed out prescriptive but a generic guide to developing instruments that take cognizance of information access. The tool hopefully fills a big void in the existing e-readiness tools with regard to information access. Similarly, the tool integrates different points of e-readiness that are separated into several e-readiness tools.

\section{REFERENCES}

[1] Shutter, J., \& de Graffenreid, E. (2000). Benchmarking the e-government revolution: Year 2000 report on citizen and business demand. Austin, San Francisco: Momentum Research Group Publications.

[2] Layne, K., \& Lee, J. (2001). Developing fully functional e-government: a four stage model. Government Information
Quarterly, 18(2), 122-136.

[3] Jaeger, P. T. (2003). The endless wire: e-government as a global phenomenon. Government Information Quarterly, 20(4), 323-331.

[4] United Nations \& American Society for Public Administration (ASPA). (2002). Benchmarking e-government: A global perspective. New York, NY: U.N. Publications.

[5] Means, G., \& Schneider, D. (2000). Meta-capitalism: The e-business revolution and the design of 21 st century companies and markets. New York: John Wiley \& Sons Inc.

[6] Schware, R., \& Deane, A. (2003). Deploying e-government programs: The strategic importance of I before E. InfoThe journal of policy regulation and strategy for telecommunications, 5(4), 10-19.

[7] Hartman, A., Sifonis, J. \& Kador, J. (2000). Net Ready: Strategies for Success in the Economy. McGraw-Hill, NY, USA.

[8] Batista, L., Badri, B., Sabourin, R. \& Thomas, M. (2013). A classifier fusion system for bearing fault diagnosis, Expert Systems with Applications 40(17), 6788-6797.

[9] Georgoulas, G., Mustafa, M.O., Tsoumas, I.P., Antonino-Daviu, J.A., Climente-Alarcon, V., Stylios, C.D. \& Nikolakopoulos, G. (2013). Principal Component Analysis of the start-up transient and Hidden Markov Modeling for broken rotor bar fault diagnosis in asynchronous machines, Expert Systems with Applications 40(17), 7024-7033.

[10] Kaya, Y. \& Uyar, M. (2013). A hybrid decision support system based on rough set and extreme learning machine for diagnosis of hepatitis disease, Applied Soft Computing 13(8), 3429-3438.

[11] Tavana, M., Zandi, F. \& Katehakis, M.N. (2013). A hybrid fuzzy group ANP-TOPSIS framework for assessment of e-government readiness from a CiRM perspective, 
Information \& Management 50(7), 383-397.

[12] Janita, I. \& Chong, W.K. (2013). Barriers of B2B e-Business Adoption in Indonesian SMEs: A Literature Analysis, Procedia Computer Science 17, 571-578.
[13] Keramati, A., Afshari-Mofrad, M. \& Kamrani, A. (2011). The role of readiness factors in E-learning outcomes: An empirical study, Computers \& Education 57(3), 1919-1929. 